\title{
Rheology and Physical Properties of Polysulfone In-Situ Reinforced with a Thermotropic Liquid-Crystalline Polyester
}

\author{
Soon Man Hong, Byoung Chul KIM, Kwang Ung KIM, \\ and In Jae CHUNG ${ }^{*, \dagger}$ \\ Polymer Processing Laboratory, Korea Institute of Science and Technology, \\ P.O. Box 150 Cheongryang, Seoul, Korea 130-650 \\ * Department of Chemical Engineering, \\ Korea Advanced Institute of Science and Technology, \\ P.O. Box 150 Cheongrayang, Seoul, Korea 130-650
}

(Received March 14, 1991)

\begin{abstract}
Blending Amoco polysulfone Udel P-1700 and Hoechst Celanese thermotropic liquid-crystalline polymer (TLCP) Vectra A-950 in a twin-screw extruder produced in-situ composites. An inclusion of TLCP did not notably change the thermal properties of polysulfone but the rheological properties were notably changed depending on the measured temperature and blend composition. In the vicinity of crystal-nematic transition temperature, an incorporation of TLCP into polysulfone increased the melt viscosity and gave rise to a large yield stress. Above the crystal-nematic transition temperature, however, TLCP dramatically decreased the melt viscosity and the resultant yield stress was very small. The tensile strength and modulus of as-spun polysulfone/TLCP fibers were increased as the TLCP content and spin draw ratio were increased. The increase in tensile strength with spin draw ratio was more noticed with the polysulfone/TLCP fiber containing higher TLCP content. Wide angle X-ray diffraction patterns suggested that the increase in tensile strength is ascribable to the enhanced molecular orientation and resultant fibrillation of TLCP. The compositional moduli of as-spun blend fibers were well fitted to the additivity rule of mixtures, viz., the Tsai-Halpin equation for the reinforcement of infinite aspect ratio.
\end{abstract}

KEY WORDS Polysulfone / Vectra A-950 / In-Situ Composite / Blend /

As-Spun Fiber / Rheology / Physical Properties /

It has long been a subject of significant commercial importance for most polymer engineers to improve the thermal and mechanical properties of organic polymers. The ways to achieve this improvement in properties include synthesis of new polymers by molecular design, blending and alloying of existing polymers, and compounding a polymer with inorganic fillers or reinforcements. For the economical and practial reasons, an incorporation of inorganic materials has been widely adopted and has been commercially successful. However, inclusion of inorganic material component frequently brings about some serious problems during the fabrication process and the service period. Abrasion of processing equipments, flow instabilities resulting from high melt viscosities, and nonuniform product properties due to poor dispersion and poor interfacial adhesion, to name a few.

Recently, the in-situ reinforcement process based on the in-situ crystallization concept gives a promising clue to solve some of these problems. ${ }^{1-3} \mathrm{Kiss}^{4}$ has succeeded in avoiding such problems by adopting an in-situ composite technology, viz., by forming the reinforcing

\footnotetext{
† To whom all correspondence should be addressed.
} 
species in the matrix polymer on the spot during the fabrication process. Some fascinating advantages of this in-situ composite over the conventional inorganic reinforced thermoplastic composites are; a much enhanced processability due to the low melt viscosities, uniform product properties resulting from better dispersion of reinforcements, and less equipment damage. Further, the detrimental mechanical properties originating from difference in thermal expansion coefficients between matrix polymer and reinforcement may be more easily controlled. Several thermotropic liquidcrystalline polymers (TLCPs) have been tested as reinforcing species for such isotropic polymer matrices as polystyrene, ${ }^{5-7}$ polycarbonate,$^{8-14}$ polyethersulfone, ${ }^{4,15}$ nylon, ${ }^{16-19}$ and poly(ethylene terephthalate). ${ }^{20-22}$

This study investigates the in-situ reinforced polysulfone systems with a thermotropic liquid-crystalline polyester. The morphology and physical properties of these blend systems are discussed in terms of blending ratio and processing conditions.

\section{EXPERIMENTAL}

The polysulfone resin tested as an isotropic matrix was Udel P-1700 (Amoco, U.S.A.), and the thermotropic liquid-crystalline polymer (TLCP) examined as a reinforcement, Vectra A-950 (Hoechst Celanese, U.S.A.). According to the supplier, Vectra A-950 is composed of $73 \mathrm{~mol} \%$ of $p$-hydroxybenzoic acid and 27 mol\% of 2,6-hydroxynaphthoic aicd. The loading levels of TLCP were 25, 50, and $75 \mathrm{wt} \%$. Both resins were dried in a forced convection oven at $100^{\circ} \mathrm{C}$ for 24 hours, and the formulated components were compounded in a Brabender twin-screw extruder at $300^{\circ} \mathrm{C}$ with purging the hopper with dried nitrogen gas.

Thermal properties were measured with a Dupont Thermal Analysis 2000 in a nitrogen atmosphere. The heating rate was $10^{\circ} \mathrm{C} \mathrm{min}^{-1}$, and the data obtained during the second heating stage were demonstrated. Melt crystal- lization temperature $\left(T_{\mathrm{c}}\right)$ and heat of crystallization $\left(\Delta H_{\mathrm{c}}\right)$ were obtained during the cooling stage, in which case the cooling rate was $10^{\circ} \mathrm{C} \mathrm{min}^{-1}$. The rheological properties were measured by Rheometrics dynamic spectrometer, RDS-7700. In the rheological measurements, a parallel-plate geometry was adopted. The spinning experiments were carried out by using a spinning capillary die attatched to the twin-screw extruder. The radius and length of the die were $2 \mathrm{~mm}$ and $20 \mathrm{~mm}$, respectively. The strand leaving the die exit was directly quenched in a water bath and drawn by take-up machine. The draw ratio was determined by dividing the capillary diameter by the diameter of spun fiber. The wide angle X-ray spectrum was obtained for the as-spun fiber by Rigaku D/Max X-Ray Diffractometer. The tensile properties of the fiber were measured by Instron, Model 4201. In the tensile measurements, the gauge length and crosshead speed were $30 \mathrm{~mm}$ and $5 \mathrm{~mm} \mathrm{~min}^{-1}$, respectively. The optical texture of these composites was observed by polarized optical microscope equipped with a hot stage (Zeiss Photomicroscope 3 Pol., Germany). The tensile fractured morphology was examined with a scanning electron microscope (SEM), Hitachi S-510.

\section{RESULTS AND DISCUSSION}

\section{Thermal Properties of Polysulfone/TLCP Blends}

Differential scanning calorimetric thermograms of various blends of polysulfone with a thermotropic liquid-crystalline polymer (TLCP) are shown in Figure 1. The neat polysulfone shows a clear glass transition at $188^{\circ} \mathrm{C}$ indicating an amorphous polymer while the neat TLCP polyester exhibits a sharp endothermic peak at $279^{\circ} \mathrm{C}$. An examination of phase morphology has proved that the endothermic peak represents a transition temperature from crystal to nematic. That is, the nematic nature of the thermotropic mesophase can be confirmed by a threadedSchileren texture observed by polarized optical 
microscope. Polarized optical texture of TLCP at two temperatures, 280 and $300^{\circ} \mathrm{C}$, are presented in Figure 2. These photomicrographs do not visualize any discernible change in the liquid-crystalline texture with increasing temperature from 280 to $300^{\circ} \mathrm{C}$. The nematic to isotropic transition temperature, however, could not be observed up to $400^{\circ} \mathrm{C}$, the heating limit of the equipment.

The polysulfone/TLCP blends exhibit thermal transitions typical of immiscible blends of

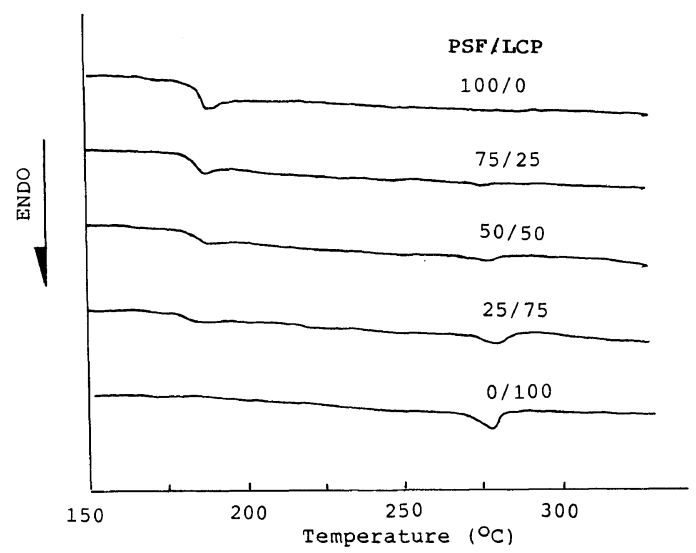

Figure 1. DSC thermograms obtained for polysulfone/LCP blends (heating rate, $10^{\circ} \mathrm{C} \mathrm{min}^{-1}$ ).

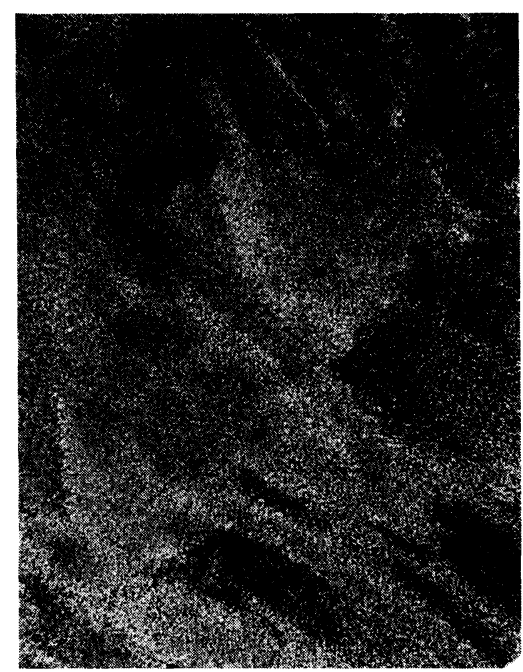

(a) At $280^{\circ} \mathrm{C}$ amorphous and crystalline polymers. As shown in Figure 1, with increasing TLCP content the glass transition temperature is lowered and the glass transition behavior gets duller. On the other hand, the endothermic peak appears to be independent of the TLCP content in the blends, and gets sharper as the loading level of TLCP is increased. For a quantitative analysis of the endothermic peaks the enthalpy change was evaluated and given in Table I. As can be predicted the enthalpy change is increased with increasing the TLCP content.

It is of practical interest to know the effect

Table I. Thermal properties of several polysulfone/LCP blends ${ }^{\mathrm{a}}$

\begin{tabular}{|c|c|c|c|c|c|}
\hline LCP & $T_{\mathrm{g}}$ & $T_{\mathrm{c}}$ & $\Delta H_{\mathrm{c}}$ & $T_{\mathrm{m}}$ & $\Delta H_{\mathrm{m}}$ \\
\hline content/\% & ${ }^{\circ} \mathrm{C}$ & ${ }^{\circ} \mathrm{C}$ & $(\mathrm{J} / \mathrm{C})$ & ${ }^{\circ} \mathrm{C}$ & $\mathrm{J} / \mathrm{g}$ \\
\hline 0 & 188.3 & - & - & - & - \\
\hline 25 & 186.2 & 237 & 0.16 & 276 & 0.17 \\
\hline 50 & 185.2 & 237 & 0.43 & 278 & 0.33 \\
\hline 75 & 180.7 & 238 & 0.83 & 279 & 0.77 \\
\hline 100 & - & 238 & 1.41 & 279 & 1.31 \\
\hline
\end{tabular}

a $T_{\mathrm{g}}$, glass transition temperature; $T_{\mathrm{c}}$, melt crystallization temperature during cooling scan; $T_{\mathrm{m}}$, crystalline to nematic transition temperature.

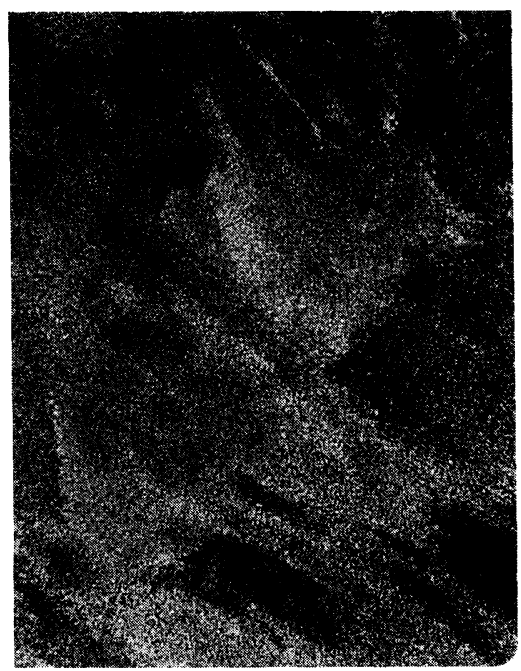

(b) At $300^{\circ} \mathrm{C}$

Figure 2. Liquid-crystalline textures of TLCP. 


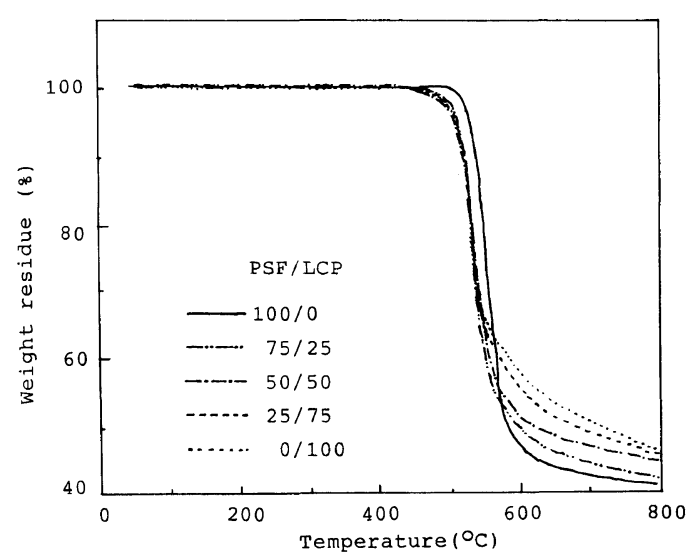

Figure 3. TGA thermograms obtained for polysulfone/TLCP blends (heating rate, $10^{\circ} \mathrm{C} \mathrm{min}^{-1}$ ).

of one component on the thermal degradation of the other component in the blend systems. Thermogravimetric curves of polysulfone/ TLCP blends are shown in Figure 3. The neat polysulfone exhibit a rapid thermal degradation above $460^{\circ} \mathrm{C}$, and the temperature leading to a maximum degradation rate is calculated to be around $530^{\circ} \mathrm{C}$. TGA study further reveals that the neat polysulfone exhibits better thermal stability than the blends with TLCP below the maximum degradation temperature. However, the polysulfone/TLCP blends show better thermal stability in the temperature range, $600^{\circ} \mathrm{C}$ through $800^{\circ} \mathrm{C}$. This suggests that TLCP enhances the overall thermal stability of polysulfone at higher temperatures. Referring to the TGA curves the weight loss reaches almost 50 to $60 \mathrm{wt} \%$ at $800^{\circ} \mathrm{C}$ depending on the blending ratio.

To give a more detailed information on the thermal degradation process the activation energy of decomposition was determined from the slope on the plots of thermal decomposition reaction rate constant against reciprocal temperature, viz., the Arrehenius plots. Variation of activation energy of decomposition with blend composition is given in Table II. It can be seen in the table that the polysulfone/TLCP blends give rise to a synergistic effect on the retardation of thermal decomposition.
Table II. Variation of activation energy of decomposition for polysulfone/LCP blends with LCP content

\begin{tabular}{cc}
\hline LCP content & $E_{\mathrm{A}}$ \\
$\mathrm{wt} \%^{\mathrm{c} \%}$ & $\mathrm{cal} \mathrm{mol}^{-1}$ \\
\hline 0 & 92.5 \\
25 & 99.8 \\
50 & 107.5 \\
75 & 94.6 \\
100 & 89.7 \\
\hline
\end{tabular}

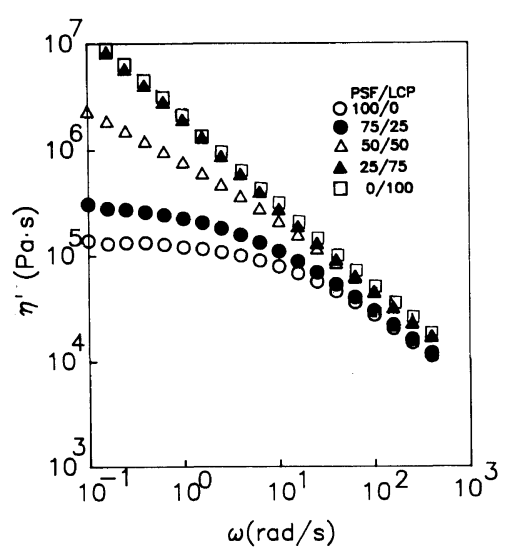

Figure 4. Viscosity curves of polysulfone/TLCP blends at $280^{\circ} \mathrm{C}$.

\section{Rheological Properties of Polysulfone/TLCP Blends}

Viscosity curves of several polysulfone/TLCP blends at 280 and $300^{\circ} \mathrm{C}$ are shown in Figures 4 and 5, respectively. The neat TLCP and polysulfone/TLCP blends containing high level of TLCP do not exhibit the lower Newtonian flow region, which is more prominent with low temperature. As well known a TLCP produces a successive phase change, solid $\rightarrow$ anisotropic containing some solid $\rightarrow$ anisotropic $\rightarrow$ isotropic, as the temperature is increased. As previously mentioned thermal along with morphological characterizations proved a crystal to nematic transition temperature of TLCP to be $279^{\circ} \mathrm{C}$. It should be noted in Figures 4 and 5 that increasing the TLCP content in the polysulfone/TLCP blends de- 


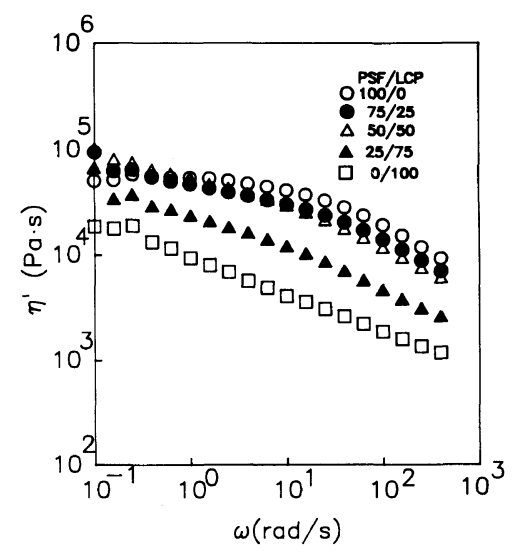

Figure 5. Viscosity curves of polysulfone/TLCP belends at $300^{\circ} \mathrm{C}$.

creases the melt viscosity of the blends over the entire frequency range tested at $300^{\circ} \mathrm{C}$. However, inclusion of TLCP raises the melt viscosity at $280^{\circ} \mathrm{C}$. Referring to the DSC thermograms, the TLCP in the blends will not fully melt to produce an isotropic liquid at $280^{\circ} \mathrm{C}$ because it begins to form a nematic texture in the vicinity of $280^{\circ} \mathrm{C}$. Thus, the anisotropic solids of unmelted TLCP may play a role of filler at this temperature. On the other hand, the reduction of melt viscosity at $300^{\circ} \mathrm{C}$ seems to result from the fact that the fully melted TLCP may impart a lubrication effect on the polysulfone/TLCP blend systems. Although little morphological change is observed with increasing temperature from 280 to $300^{\circ} \mathrm{C}$ as presented in Figure 2, the value of yield stress determined by the intercept on the Casson-type plot, a plot of square root of loss modulus $\left(G^{\prime 1 / 2}\right)$ against square root of angular frequency $\left(\omega^{1 / 2}\right)$, makes a large difference with increasing temperature as shown in Figures 6 and 7. As well recognized, the non-zero yield stress assessed on the Casson plot is related to the disappearance of lower Newtonian flow region in the viscosity curves presented in Figures 4 and 5. Rheologically speaking, the non-zero yield stress is a characteristic feature of inorganic material filled systems. In general the yield stress is increased as the loading level

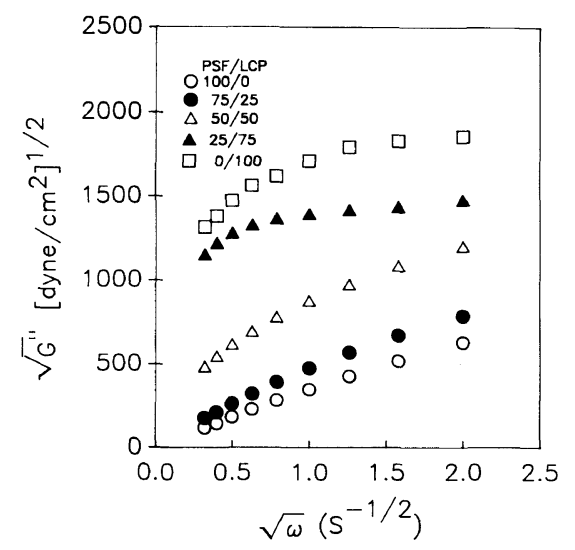

Figure 6. Casson-type plot of polysulfone/TLCP blends at $280^{\circ} \mathrm{C}$.

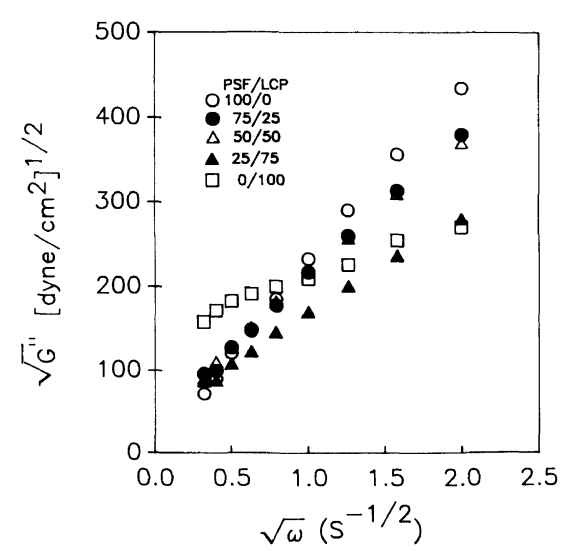

Figure 7. Casson-type plot of polysulfone/TLCP blends at $300^{\circ} \mathrm{C}$.

of inorganic material is increased. Therefore, the abrupt reduction in yield value by increasing the temprature from 280 to $300^{\circ} \mathrm{C}$ implies that a serious change in the liquid-crystalline superstructure takes place although it is impossible to observe it microscopically. Thus, the large positive yield value at $280^{\circ} \mathrm{C}$ suggests that the TLCP forms a heterogeneous anisotropic phase and a much smaller yield value at $300^{\circ} \mathrm{C}$ is indicative of a reduced heterogeneity with increasing temperature. Similar phenomena were also observed by other researchers. ${ }^{5,10,11,15,16}$

Another rheological characterization has 


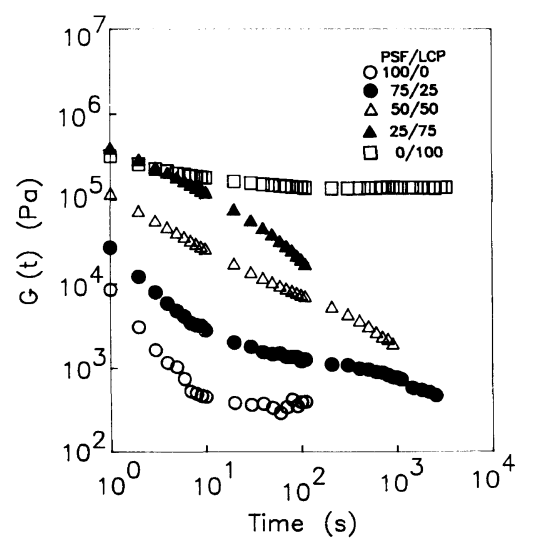

Figure 8. Relaxation moduli of polysulfone/TLCP blends with time at $280^{\circ} \mathrm{C}$.

been attempted to investigate the shear stress relaxation behavior. ${ }^{12}$ In the measurements of the stress relaxation modulus, $G(t)$, the decay of stress with time makes it possible to assess the bulk characteristics of a polymeric material. Figure 8 shows relaxation process of various polysulfone/TLCP blends with time at $280^{\circ} \mathrm{C}$. A notable difference in relaxation behavior can be observed in this figure depending on the TLCP content in the polysulfone/TLCP blends. The neat polysulfone yields a very low relaxation modulus, and the relaxation modulus rapidly decreases with time at $280^{\circ} \mathrm{C}$. Further, the rate of stress relaxation is faster at longer relaxation time. The time effect in this region is ascribable to the short-range motions of relatively small segments of the polymer molecules, indicating a rubbery state. On the other hand, the neat TLCP shows a high relaxation modulus, which is very slowly decreased with time at $280^{\circ} \mathrm{C}$. On the whole, the polysulfone/TLCP blends exhibit a relaxtion behavior different from that of the neat polysulfone or the neat TLCP but produce an intermediate relaxation behavior of the two neat resins. This is a clear evidence for a good distribution of TLCP within polysulfone matrix and offers a clue to account for the self-reinforcing mechanism of TLCP.

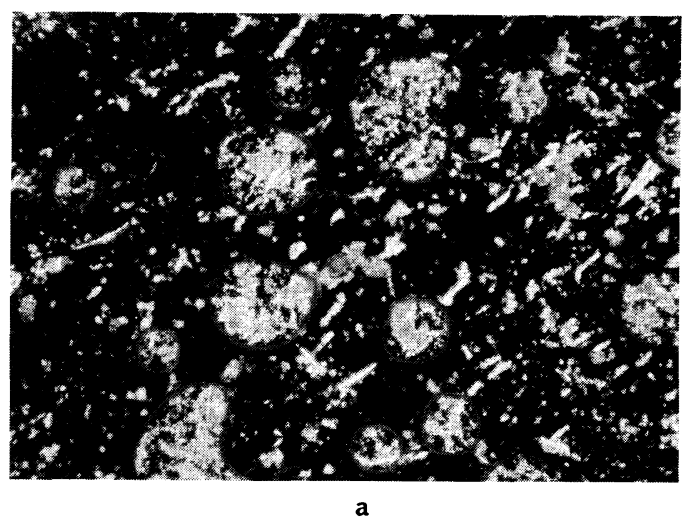

a

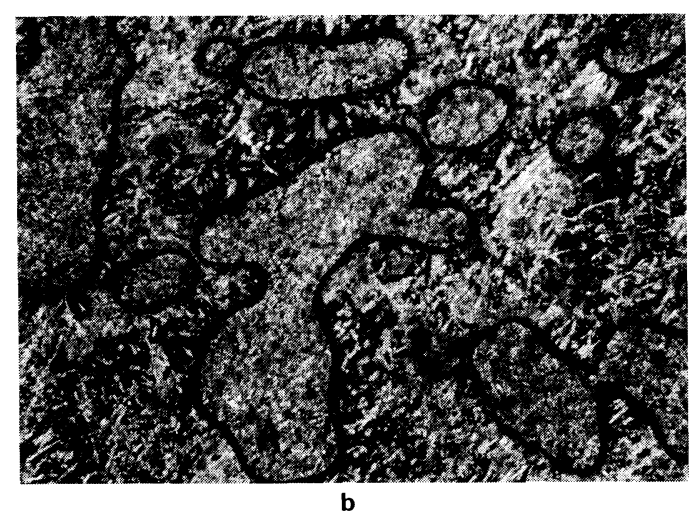

Figure 9. Polarized optical micrographs taken of polysulfone/TLCP at $320^{\circ} \mathrm{C}$ : a, 75/25; b, 25/75.

\section{Morphology-Property Relationship in As-Spun Polysulfone/TLCP Blend Fibers}

The optical characteristics of polysulfone/ TLCP blends at $320^{\circ} \mathrm{C}$ observed by polarizing optical microscope equipped with a hot stage are presented in Figure 9. Two distinct phase structures are noticeable in these polarized optical micrographs. The black area represents the isotropic phase of polysulfone and white droplets stand for the anisotropic phase of TLCP. A careful observation further reveals a poor interfacial adhesion between these two phases.

The tensile strength of as-spun fibers of polysulfone, polysulfone/TLCP blends, and TLCP, spun at $300^{\circ} \mathrm{C}$, is plotted against spin draw ratio in Figure 10. Three things are worth 


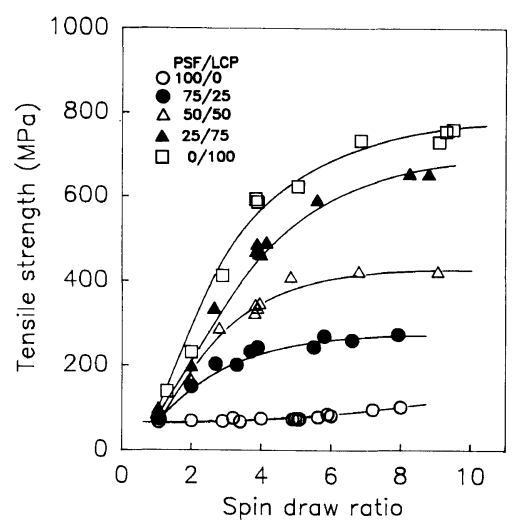

Figure 10. Variation of tensile strength of as-spun polysulfone/TLCP fibers with TLCP content and spin draw ratio.

mentioning in the strength-strain curve. Firstly, an increase of TLCP content increases the tensile strength of the blend fibers. Secondly, the tensile strength is increased as the spin draw ratio is increased. Finally, an increase in tensile strength with increasing spin draw ratio is more prominent when the loading level of TLCP is higher. The microstructures of tensile fractured surfaces of these as-spun fibers with draw ratio 4 are shown in Figure 11. Morphologically, the increased tensile strength of the as-spun fiber containing TLCP is ascribable to the fact that the TLCP phase develops a fibrillar structure, particularly with TLCP rich blends, as shown in the figure. In these SEM photomicrographs, the ellipsoidal TLCP domains embedded in amorphous polysulfone matrix are expected to play a role of reinforcements. The wide angle X-ray diffraction (WAXD) patterns of these as-spun fibers obtained at the spin draw ratio of 4 are shown in Figure 12. As can be seen in the diffraction patterns increasing the TLCP content in the blends enhances the fiber orientation because of higher degree of anisotropy in polymer crystallites. In Figure 13 the orientation angle of as-spun polysulfone/ TLCP fibers is plotted against the TLCP content. The orientation angle is gradually decreased as the TLCP content is increased.
As one might surmise a better fiber orientation can provide a higher tensile strength at a given composition. Thus, the enhanced fibrer orientation as a result of orientation of TLCP molecules induced by elongational flow can also be regarded as additional contribution to the improvement of tensile strength. Similar results were reported by Jung and $\mathrm{Kim}^{9}$ and Crevecoeur and Groeninckx ${ }^{6}$ for different in-situ composite systems.

As already shown in Figure 10, the tensile strength is increased as the spin draw ratio is increased. Figure 14 accounts for the effect of spin draw ratio on the morphology of as-spun polysulfone/TLCP $(50 / 50)$ blend fibers obtained at different spin draw ratios. The SEM photomicrographs of tensile fractured surfaces represent an increase of fiber orientation with increasing the TLCP content. A careful observation of these photomicrographs further reveals that at the fixed composition the blend fiber obtained at a higher spin draw ratio gives rise to a greater elongation of liquid-crystalline domains. In fact, it is seen that the Vectra domains vary from ellipsoidal particles to fibrillar structure as the spin draw ratio is increased. As a rule, a reinforcement with larger aspect ratio produces higher tensile strength at a given loading level of reinforcement. Therefore the higher tensile strength at the higher spin draw ratio at a fixed composition is attributable to the greater elongation of TLCP phase.

Assuming a perfect mathematical surface between matrix and reinforcing fiber, Tsai and Halpin $^{23}$ suggested an equation which relates the modulus of composite in the fiber direction $\left(E_{\|}\right)$to the volume fraction of reinforcing fiber $\left(V_{\mathrm{f}}\right)$ :

$$
\begin{gathered}
E_{\|}=E_{\mathrm{m}} \frac{1+\theta \lambda V_{\mathrm{f}}}{1-\lambda V_{\mathrm{f}}} \\
\lambda=\frac{E_{\mathrm{f}} / E_{\mathrm{m}}-1}{E_{\mathrm{f}} / E_{\mathrm{m}}+\theta}
\end{gathered}
$$

in which, $E_{\mathrm{m}}$ is the modulus of matrix polymer, 


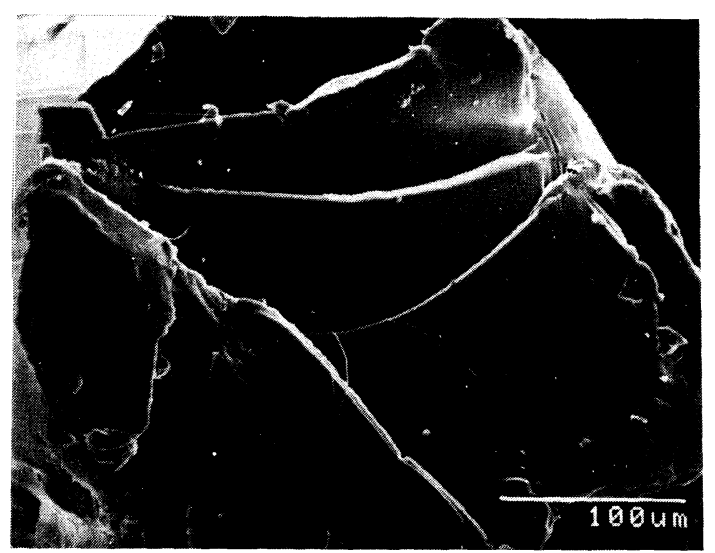

$\mathbf{a}$
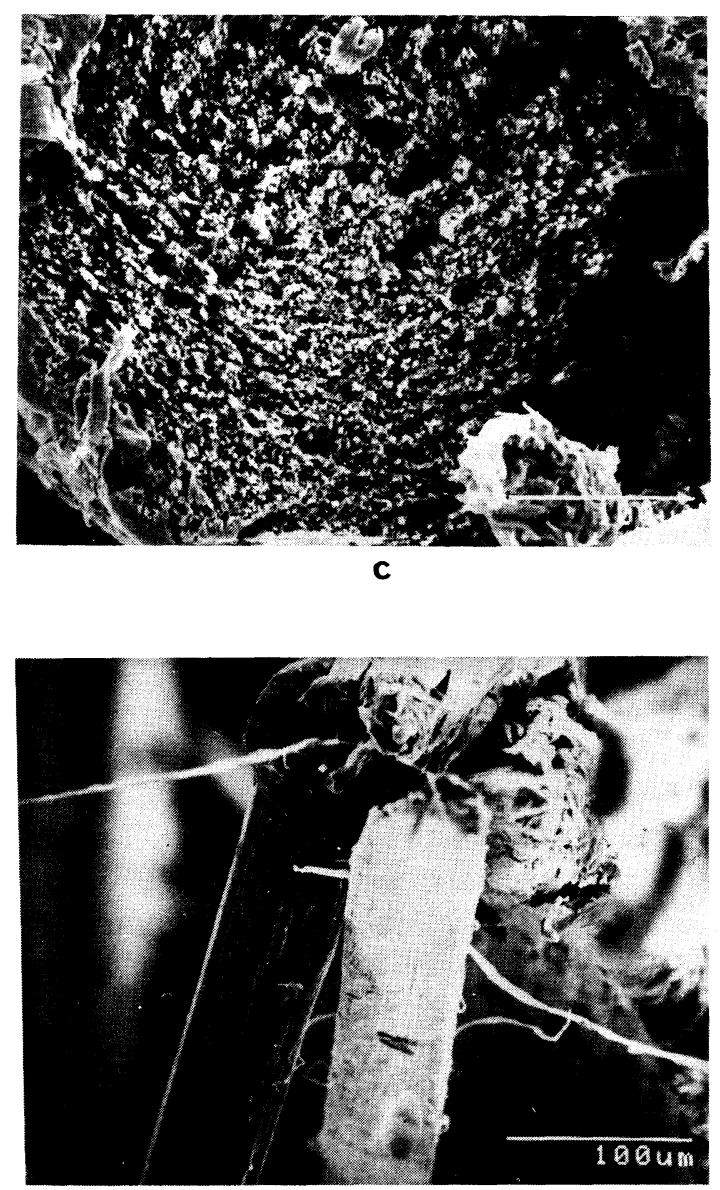

e

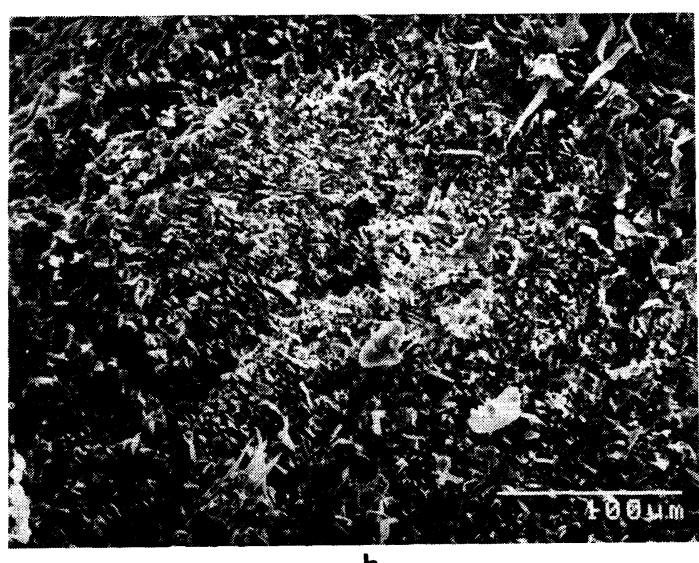

b

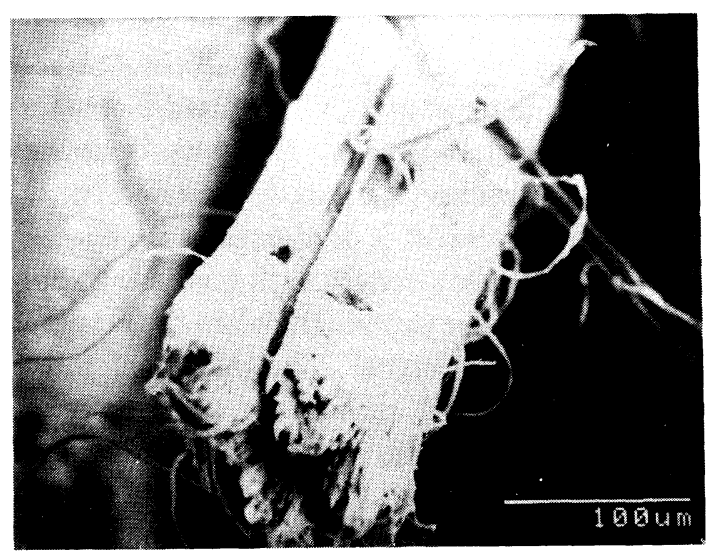

d

Figure 11. SEM photomicrographs of tesnsile fractured surfaces of polysulfone/TLCP fibers at the draw ratio 4 $(\times 300)$. a, $100 / 0 ; b, 75 / 25 ; \mathrm{c}, 50 / 50 ; \mathrm{d}, 25 / 75 ; \mathrm{e}, 0 / 100$. 


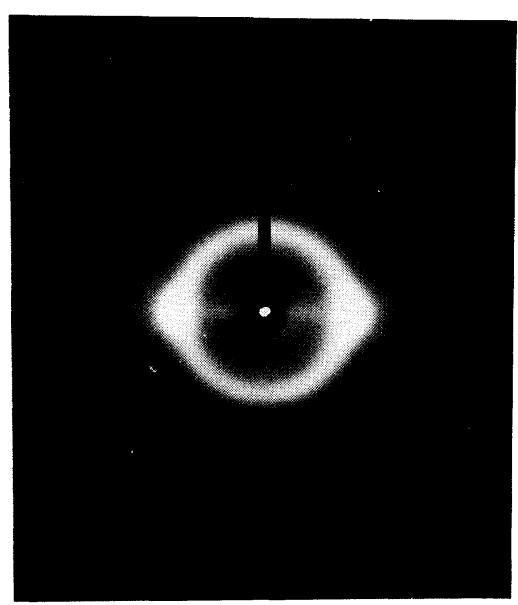

$\mathbf{a}$

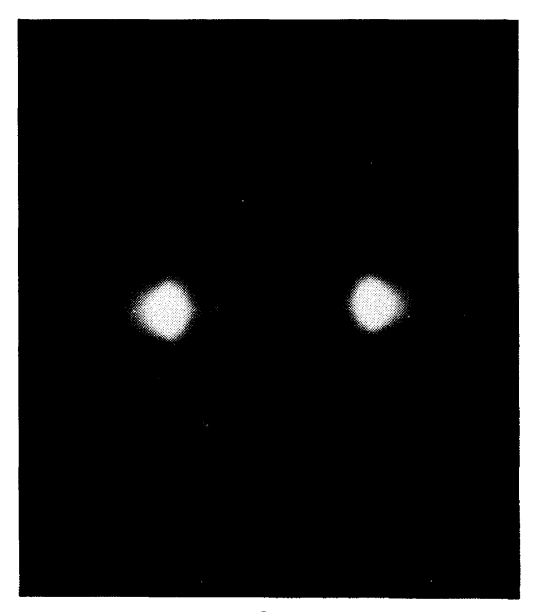

C

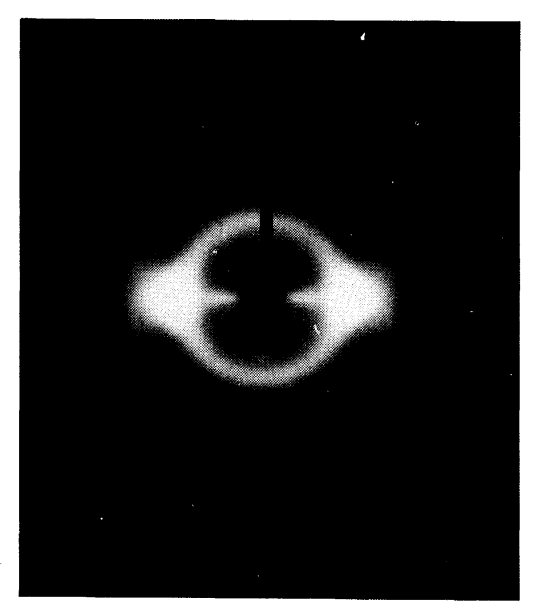

b

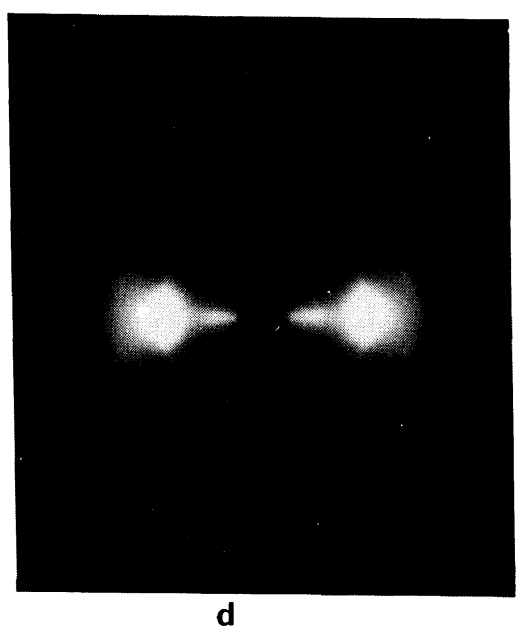

Figure 12. Wide angle X-ray diffraction patterns of melt-spun polysulfone/TLCP fibers obtained at the spin draw ratio 4. a, 75/25; b, 50/50; c, 25/75; d, 0/100.

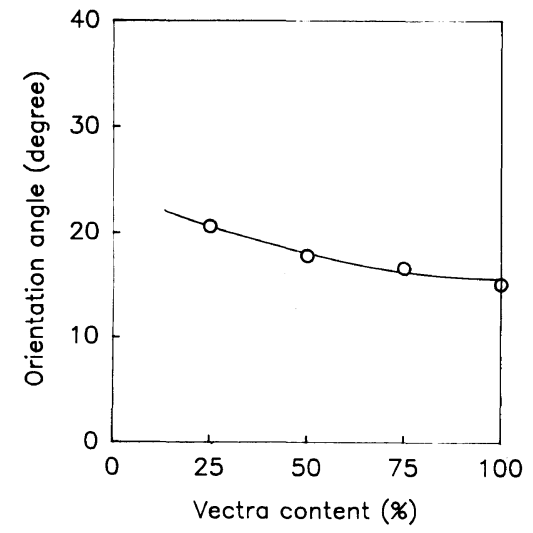

Figure 13. Orientation angle of as-spun polysulfone/ TLCP fibers obtained at the spin draw ratio 4 as a function of LCP content. 

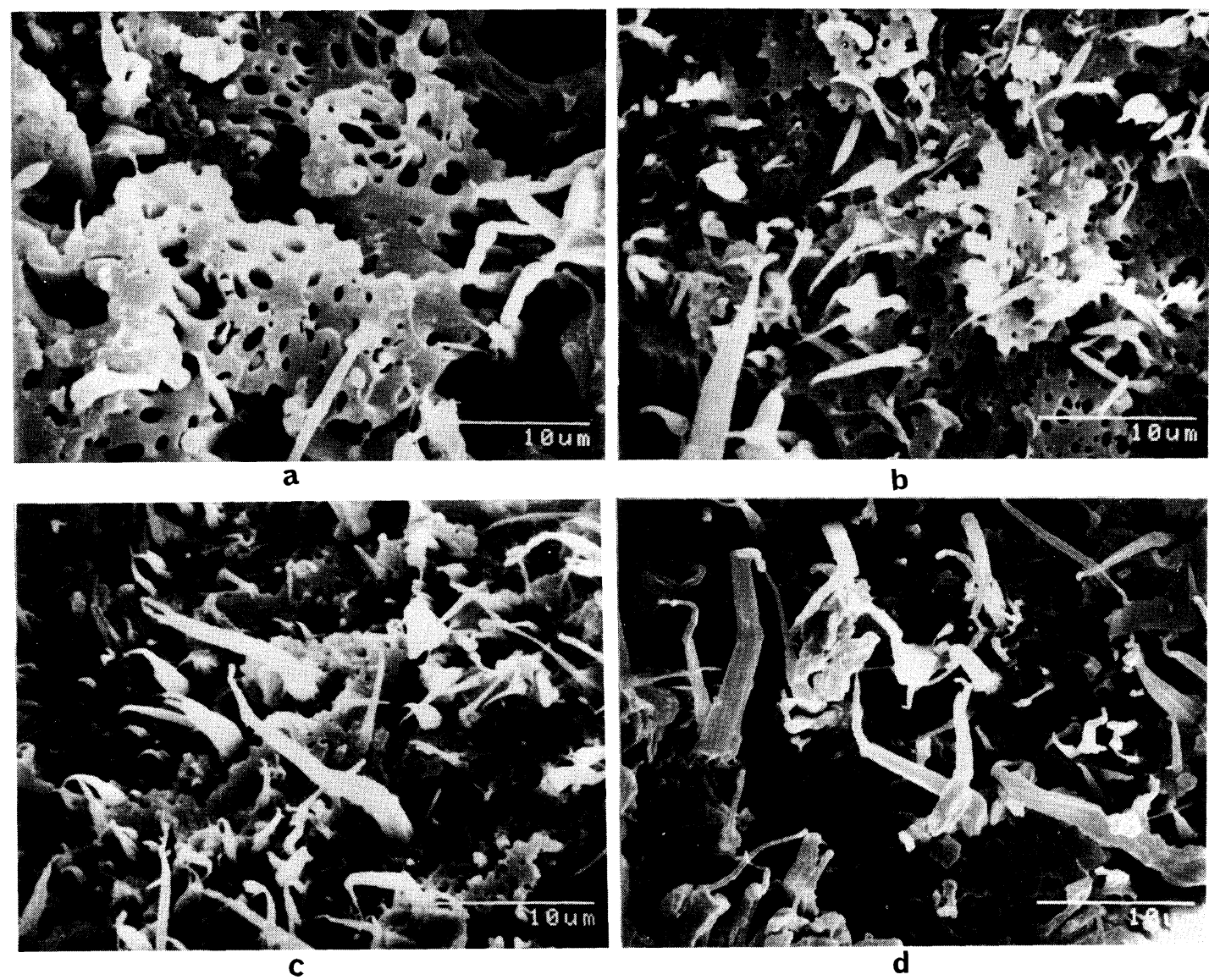

Figure 14. SEM photomicrographs of tensile fractured surfaces of polysulfone/TLCP fibers showing the effect of draw ratio on the fibrillation of TLCP phase. $a, D R=1 ; b, D R=2 ; c, D R=4 ; d, D R=8$.

$E_{\mathrm{f}}$, the modulus of reinforcing fiber, $L / D$, the aspect ratio of the reinforcing fibers, and $\theta=2(L / D)$. In the limiting case of infinite aspect ratio, this equation naturally reduces to the rule of mixtures for modulus against composition. The modulus calculated by the TsaiHalpin equation is plotted against the volume fraction of fibers of different aspect ratios in Figure 15. Two parameters adopted in the calculation of the equation, $E_{\mathrm{m}}=2.6$ and $E_{\mathrm{f}}=52.5 \mathrm{Gpa}$, were experimentally determined. The modulus of blend fibers was measured for the melt spun fibers of spin draw ratio 8 . It is noted that the rule of mixtures may be applied if the aspect ratio of the

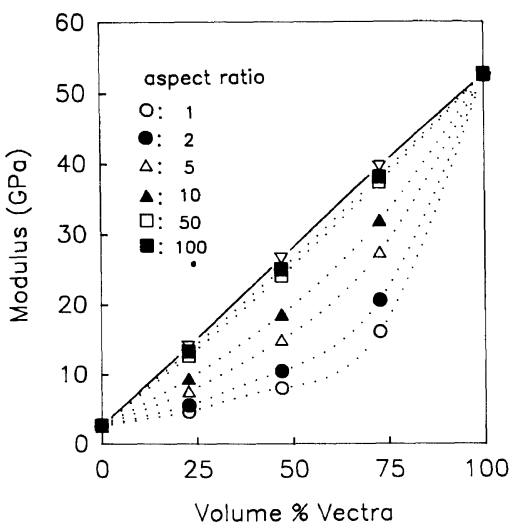

Figure 15. Graphic representation of the Tsai-Halpin equation with $E_{\mathrm{m}}=2.6$ and $E_{\mathrm{f}}=52.5 \mathrm{GPa}$ at the spin draw ratio 8 . ---, calculated; —-, experimental. 
reinforcing fiber exceeds 100 , denoted by $\nabla$. As already shown in SEM photomicrographs, the reinforcing TLCP fibriles embedded in polysulfone/TLCP fibers under consideration possess aspect ratios of nearly infinite. In addition, they show almost a perfect orientation in the fiber direction. In consequence, the blend fibers yield a linear relationship between modulus and volume fraction of TLCP. Similar results were also reported by Crevecoeur and Groeninckx $^{6}$ for the PPE/PS/Vectra A-950 systems.

\section{CONCLUSION}

The blends of two immiscible polymers, an amorphous polysulfone and a thermotropic liquid-crystalline polymer (TLCP), were investigated in terms of rheology, morphology, and physical properties. A TLCP had a profound influence on the rheological properties. It increased the melt viscosity in the vicinity of the crystal-nematic transition temperature while it decreased the melt viscosity above the temperature. Further, the TLCP blend systems exhibited a non-zero yield stress. The tensile strength and modulus of as-spun blend fibers were increased as the TLCP content and the spin draw ratio were increased, which was more prominent with higher TLCP level. The wide angle X-ray diffraction patterns ascribed the increased tensile strength to the enhanced molecular orientation and fibrillation of TLCP. The compositional moduli of as-spun blend fibers were well fitted to the additivity rule of mixtures.

\section{REFERENCES}

1. J. R. Joseph, J. L. Kardos, and L. E. Nielsen, J. Appl. Polym. Sci., 12, 1151 (1968).

2. J. L. Kardos, W. L. McDonnel, and J. Raisoni, J. Macromol. Sci. Phys., B6, 397 (1972).

3. A. Siegmann, M. Narkis, M. Puterman, and A. T. DiBendetto, J. Polym. Sci. Phys., 17, 225 (1979).

4. G. Kiss, Polym. Eng. Sci., 27, 420 (1987).

5. R. A. Weiss, H. Wansoo, and L. Nicolais, Polym. Eng. Sci., 27, 684 (1987).

6. G. Crevecour and G. Groeninckx, Polym. Eng. Sci., 30, 9, 532 (1990).

7. B. R. Bassett and A. F. Yee, Polym. Eng. Sci., 11, 1,10 (1990).

8. A. I. Isayev and M. Modic, Polym. Compos., 8, 158 (1987).

9. S. H. Jung and S. C. Kim, Polym. J., 20, 73 (1988).

10. D. Acierno, E. Amendola, C. Carfagna, L. Nicolais, and R. Nobile, Mol. Cryst. Liq. Cryst., 153, 553 (1987).

11. M. R. Nobile, E. Amendola, L. Nicolais, D. Acierno, and C. Carfagna, Polym. Eng. Sci., 29, 224 (1989).

12. T. M. Malik, P. J. Carreau, and N. Chapleau, Polym. Eng. Sci., 29, 600 (1989).

13. A. Kohli, N. Chung, and R. A. Weiss, Polym. Eng. Sci., 29, 573 (1989).

14. B. Y. Shin and I. J. Chung, Polym. J., 21, 851 (1989).

15. S. G. James and A. M. Donald, Mol. Cryst. Liq. Cryst., 153, 501 (1987).

16. A. Siegman, A. Dagan, and S. Kenig, Polymer, 26, 1325 (1985).

17. T. S. Chung, Plast. Eng., Oct., 39 (1987).

18. B. Y. Shin and I. J. Chung, Polym. Eng. Sci., 30, 22 (1990).

19. F. P. L. Mantia, A. Valenza, M. Paci, and P. L. Magagnini, Polym. Eng. Sci., 30, 7 (1990).

20. W. Brostow, T. S. Dziemianowicz, J. Romanski, and W. Weber, Polym. Eng. Sci., 28, 785 (1988).

21. C. U. Ko and G. L. Wilkes, J. Appl. Polym. Sci., 37, 3063 (1989).

22. A. M. Sukhadia, D. Done, and D. G. Baird, Polym. Eng. Sci., 30, 519 (1990).

23. J. C. Halpin and J. C. Kardos, Polym. Eng. Sci., 16, 344 (1976). 